\title{
Creating customer-centric organisations: The value of design artefacts
}

\author{
Jacqueline (Jax) Wechsler ${ }^{\mathrm{a} *}$ and Jochen Schweitzer ${ }^{\mathrm{b}}$ \\ ${ }^{a}$ Sticky Design Studio, Sydney, Australia; ${ }^{b}$ University of Technology Sydney Business \\ School, Sydney, Australia
}

\begin{abstract}
More organisations are adopting customer-centric innovation practices to increase business value; however, very little is known about the factors driving customer-centric innovation or the conditions under which innovation succeeds. Similarly, very little is known about the role of design artefacts as inputs in customer-centric innovation processes or as instruments that support the organisational change required for successful change. A practice-led case study was conducted to examine the role of design artefacts and to demonstrate how they are flexible and persuasive tools that mediate the social and intertwined demands of customer-centric innovation strategies. Five distinct roles of design artefacts are proposed and their value in contributing to innovation and organisational change are considered.
\end{abstract}

Keywords: design artefacts; design methods; customer-centricity; organisational change

\section{Introduction}

As a key strategic resource, the capacity to innovate has become very important to commercial, non-commercial and government organisations globally. Innovation advances people's wellbeing, their relationship with the environment, organisational efficacy and profitability. Much can be achieved by adopting a customer-centric approach to innovation; however, many challenges still remain (Bucolo, Wrigley and Matthews 2012). Recent research has shown that this approach involves many aspects and relationships including, for example, design processes (Dorst 2011) and design mindsets (Schweitzer, Groeger and Sobel 2016). Yet, the absence of theoretical support for customer-centricity within the broader management literature has led to ongoing 
debates in relation to the effects of practically adopting and successfully implementing this approach to innovate products and services, organisational strategies (Clegg et al. 2017), and culture and leadership (Schweitzer 2014). Further, very little is known about the role of design artefacts in supporting an organisation to be customer focused, or the changes that need to be implemented when such a strategy is adopted.

The existing literature discusses the effect design has on organisations in relation to their products, processes and strategies (e.g., Cooper, Junginger and Lockwood 2011), as well as its contribution to innovation management and market-oriented thinking (e.g., Clegg et al. 2017). However, the focus of this discourse is limited to the effect of the design process as a whole or to the influence of designed outputs (such as products, services and apps, among others), rather than specific design artefacts or the tools used within design processes and their consequent effect on market orientation and customer-centricity.

Adding to the complexity is that, to date, definitions of what artefacts are have mostly been vague. Researchers widely agree that artefacts are essential to 'getting things done' in organisations (Knorr Cetina 1997; Orlikowski 2002); however, very little agreement exists on how managers successfully use and produce design artefacts (both at the organisational and individual levels) when pursuing innovation or implementing change. We define design artefacts as visual artefacts used within innovation and design processes, and any visual objects towards which and with which individuals act. This includes only artefacts that have been created during the design process such as prototypes, journey maps and wire frames. It does not include artefacts that constitute a final product or service.

We conducted a single instrumental case study (Stake 1995) of a project that sought to improve the ordering and activation services related to complex information 
technology and telecommunications products. For this, we adopted an ethnographic and practice-led research approach and undertook an investigation of situated design practices in a complex practice context (Mafe and Brown 2006). Our case study considered design artefacts in relation to their social contexts to clarify their mediatory roles within customer-centric innovation processes and to highlight the potential of design artefacts to support organisational change.

First discussed are related readings about customer-centricity and organisational change, design artefacts as boundary objects and designers' roles as knowledge brokers. Materials and methods are also explained, including details about the case. Next, five propositions for artefacts' supporting roles in customer-centricity are presented in Sections 5 and 6.

\section{Background}

\subsection{Customer-centricity and Organisational Change}

Human-centred innovation is based on 'customer insights' or the knowledge gained by interacting directly with consumers to understand their values and meaning-based needs (Beckman and Barry 2007). In business practices, human-centred innovation is also referred to as 'customer-centred innovation' or 'customer-centricity'. Design professionals have long used ethnographic research approaches within design practice; however, more recently, innovation and management writers have also advocated for the adoption of ethnographic approaches in relation to customer-centricity (Beckman and Barry 2007; Liedtka and Ogilvie 2011). Previous research has shown that design processes and artefacts are commonly applied within the business context and that design practices and tools add value to businesses (Leung et al. 2016; Veyzer and Borja De Mozata 2005). Numerous studies focusing on customer-centricity have also shown 
that the application of design tools and methods (e.g., 'personas', 'prototyping', 'scenarios' and 'customer journey maps') are endemic in design practice (Hanington and Martin 2012). Indeed, these valuable methods provide deep insights into customer needs and inform human-centred innovation processes (Manning, Bodine and Bernoff 2012; Schrage 1993). Further, customer-centricity is critical to gaining a competitive advantage in business (Galbraith 2005; Manning Bodine and Bernoff 2012).

However, in both the design and business literature, understandings of how customer-centricity is enabled within organisations are limited (Johnston and Kong 2011). Many have also found it difficult to sustain a customer focus over time because it is contrary to the way in which they work, especially as many organisations centre on efficiency and quantitative metrics. Adopting a customer-centric perspective requires epistemological and attitudinal shifts (Dunne 2011). Thus, if customer-centred innovation is to be achieved, organisational transformation is also required. This could include changes to culture, processes and structure that are both challenging and time consuming. Recent studies identified some of the relationships between design (thinking) practices and organisational change and culture (Buchanan 2015; Elsbach and Stigliani 2018), but understandings of the role of design artefacts in facilitating changes towards customer-centricity remain limited.

\subsection{Design Artefacts as Boundary Objects}

Design artefacts help to get things done. Previous research has shown that material artefacts play important mediatory and enabling roles in organisational and interorganisational innovation processes (Rafaeli and Vinai-Yavetz 2004b, 2006). The effects of different artefacts (e.g., Gantt charts, texts and documents, visual representations and drawings) have been analysed and proven useful in organisational learning, knowledge and management (Hutchins 1995; Wenger 1998, 2000) or as 
collaboration enablers (Perry and Sanderson 1998; Star and Griesemer 1989), coordination devices (Henderson 1991) and as socio-material objects that mediate the social and material nature of work practices (Orlikowski 2002, 2006, 2007). However, previous studies have also largely focused on how materiality and artefacts support product development processes.

Among people, artefacts facilitate knowledge sharing and transformation, and play practical, political and persuasive roles (Kimble, Grenier and Goglio-Primard 2010; Roth and McGinn 1998). The idea of an 'artefact as a boundary object' explains both their different roles and their implicit functions in social mediation. Notably, boundary objects refer to the brokering and boundary-spanning capabilities of artefacts across functional domains within collaborative work (Star and Griesemer 1989). These objects create a shared language for individuals and ably represent their knowledge, and can also provide one with a concrete means for specifying and learning about any differences, dependencies and what is new across a given (knowledge) boundary. Additionally, boundary objects facilitate the process by which individuals transform the knowledge being used and apply what they know to transform existing problem-related knowledge (Carlile 2006).

Carlile (2002) outlines the two key tenets of boundary object artefacts: i) boundary objects are practical, as they enable a shared means of representation and a specification of any differences at the boundary; and ii) boundary objects are political, as they facilitate knowledge transformation. Thus, if innovation requires boundary spanning, the act of deciding which artefacts to share, with whom and when could be both a practical and political decision. Wenger (2000) conceptualized these decisions acts as brokering or as processes of translation, coordination and alignment between 
perspectives. Brokers move knowledge from one place to another and bring back news from the forefront.

\subsection{Designers as Knowledge Brokers}

Designers who create and employ artefacts can be considered 'knowledge brokers' (Hargadon and Sutton 2000), who use boundary objects to broker customer-centric knowledge. Essentially, such use sees artefacts function as conscription devices (Henderson 1999) to enlist participation in organisational settings. In the literature Wagner (2000) discussed the significant and persuasive roles of artefacts in collaborative work. Similarly, artefacts are also critical to customer-centric innovation contexts in which they function to mediate social and political processes and collective actions.

Understandings of the enabling roles of artefacts in organisational contexts are well established; yet, gauging their functions in organisations attempting to move towards customer-centricity remains limited and vague. Thus, this case study sought to determine if and how design artefacts could be used to support the organisational change required in designing and delivering customer-centric products and services. To answer these questions, we adopted a theoretical perspective of design artefacts as boundary objects and acted from the understanding that the designer is the knowledge broker in the context of organisational change towards customer-centricity. We also examined the role of design artefacts as flexible tools that mediate the social and interlinked demands of innovation initiatives in a specific organisation.

Studying how designers (and non-designers) consider and use design artefacts will increase knowledge of the enabling and mediatory roles of both design practices and artefacts in complex social innovation contexts (the very situation that countless organisations are presently facing). The central objective of our research was to gain a 
better understanding of how design artefacts function to facilitate and motivate collective action, and to enable communication and transformation.

\section{Materials and Methods}

A single in-depth case study was conducted to examine the role of design artefacts and to understand whether and how they support customer-centric innovation. The organisation selected for review had a confident strategic intention to pursue customercentricity. This allowed us to undertake a deep analysis of the contextual factors affecting the roles of a range of artefacts.

We also adopted a researcher-as-instrument (Robson 1995) approach. Within this approach, the researcher was the lead designer of the case project, and their relationships with those under investigation were examined (MacDonald 1994). Multiple data collection methods and sources were employed, including participant observation, qualitative interviews, document collection and the use of thick descriptions (Geertz 1973). For example, participant observations and interviews were conducted with artefact recipients and design practitioners in similar roles. Additional data sources included intranet and public website content, emails, field notes, physical artefacts, memorandums and artefacts produced by other designers for other projects.

Sampling was opportunistic (Miles and Huberman 1994), which was not ideal. However, due to the covert nature of the study, it was the only approach available. In the early phase, we had limited access to conduct interviews with diverse organisational members, most notably members of the senior leadership team, providing insights based on a restricted representation of perspectives. To gain further valuable views, we also obtained additional perspectives from stakeholders at different levels of seniority. At the end of the project we assumed an overt role, which allowed us to conduct further 
interviews with the participants of the final project presentation, who had been invited to participate in the study.

Semi-structured interview guides and a detailed research protocol (Yin 2003) were used to conduct a total of 13 interviews over two years. The majority of interviews occurred within three months of the final delivery of the project results, but follow-up interviews were later conducted with three participants some five to six months after.

The activities and contextual factors associated with the defined activity systems (i.e., the individual, team, project and organisational activities and contextual factors) were considered during data collection and analysis. Participants were asked to describe any challenges they experienced when undertaking their work activities, which enabled participants to explicate any contradictions located within the different activity systems (Engeström 1999). Data were then collected and iteratively analysed over an 18-month period that compried three distinct phases, each of which used different approaches.

A constructivist grounded theory approach was adopted for the data analysis (Mills, Bonner and Francis 2006; Seaman 2008), as the study relied on predefined theoretical concepts. Different analytical procedures were applied to each phase of the research, including concurrent collection and the coding and double coding of data (Krefting 1991).

\section{The Case Study: Redesigning Online Order and Activation Processes}

This case study was conducted at an Australian ASX-listed company with over 40,000 employees. The company offers a broad range of technology products and services, and, two years before the project commenced, had appointed a chief executive officer who was committed to building a customer-centric organisation. The organisation was commonly employing human-centred design approaches for product and service development and had several dedicated design teams. While this context created 
favourable conditions for design experimentation, it also created a limitation for replicating the findings.

The business strategy motivating this project was to improve the online ordering capability of a specific group of business-to-business customers who were responsible for selling products. The project team adopted a customer-centric approach to design new online ordering and activation services, and the researcher was hired as a 'customer-centred design lead' to work with the internal user-experience group for five months.

The objective of the user-experience design project was to deliver a conceptual design including wire frames (i.e., blueprints or visual specifications for online services) to improve online ordering. The project deliverable would support the development of a business case study so that a project team could be established and the solution brought to market.

The key sponsor of the project was the design director; however, there was an implied and strategic obligation to also connect with other stakeholders who would potentially fund and build the suggested solution. Given that the lead designer's tenure at the company was short, it was also important that the knowledge related to this project was codified and transferred in an accessible way.

As such, the project had four phases:

(1) The Listening Phase: During this phase, the team set out to i) understand the current processes for ordering and activating products, as experienced by internal staff and customers; ii) consider existing challenges with internal systems that may be common to both staff and customer groups; iii) understand customer work contexts and their dependent organisational processes; and iv) understand customer challenges and needs. The team used 'affinity 
diagramming' to gain insights and prove that the current ordering systems and processes required improvement.

(2) The Defining Phase: During this phase, the lead designer created artefacts for 'design synthesis', 'meaning-making' and 'reflection in action'. Specifically, the designer considered the information needs of different stakeholders and created distinct artefacts to satisfy specific information needs and preferences.

(3) The Designing Phase: During this phase, team members engaged in iterative sketching and conducted a workshop with 10 business customers. Here, participants reviewed and refined preliminary sketches for a web portal. The team then transformed the designs into more detailed wire frames.

(4) The Delivery Phase: During this phase, the project outcomes were shared in a meeting with 40 internal stakeholders through video and telephone conferences. The project deliverables were subsequently hosted on a website that could be accessed online during the meeting.

Figure 1 shows the project's design and research activities, and Table 1 provides an overview of each project phase, summarizes the activities completed in the project and describes the artefacts that were produced and socialized. Table 2 lists the project artefacts as they were shared. 
Figure 1. Research and design activities during the listening, defining and designing phases of the project.

\section{PROJECT ACTIVITIES}

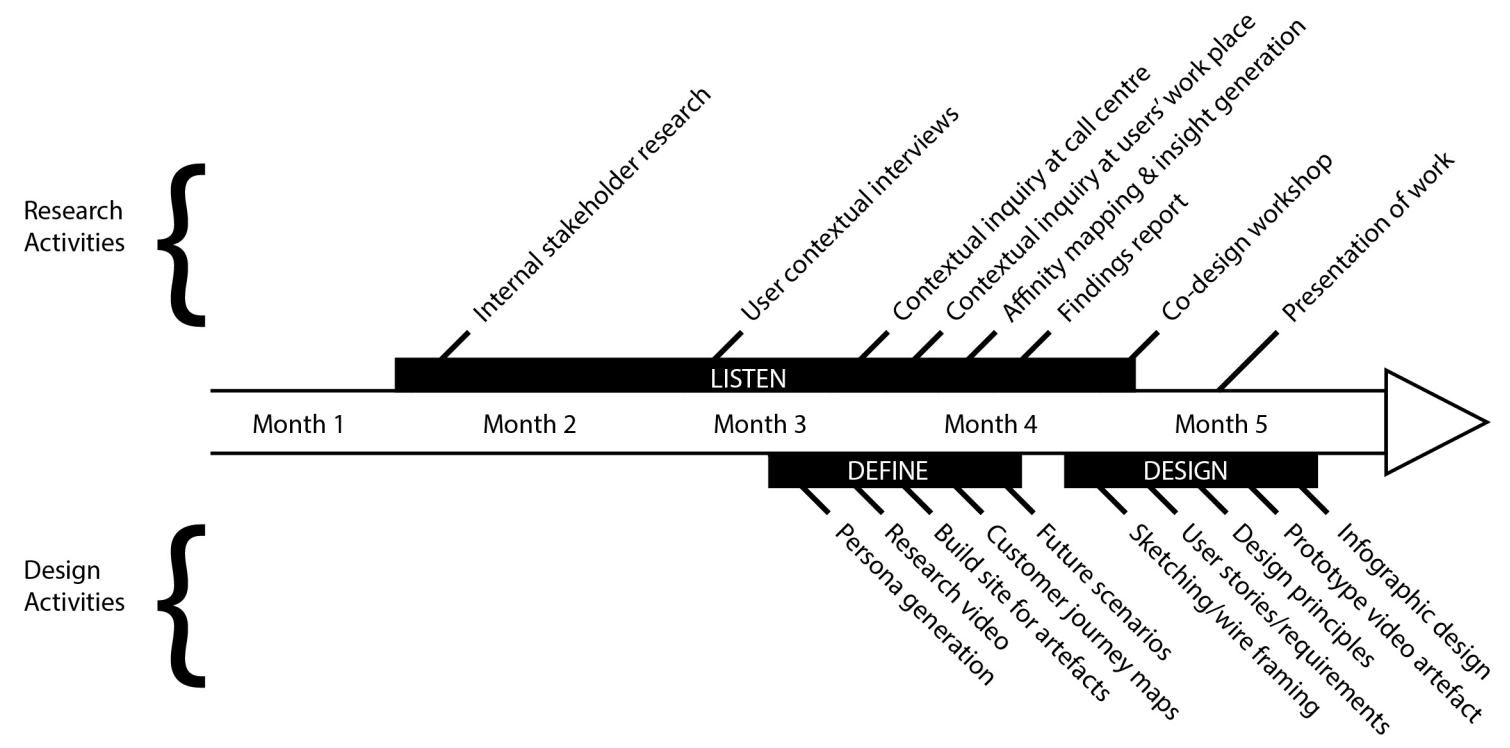

Table 1. Activities and artefacts delivered in different project phases.

\begin{tabular}{|c|c|c|}
\hline Phase & Activity & Artefacts \\
\hline Listening & $\begin{array}{l}\text { Stakeholder qualitative } \\
\text { research }\end{array}$ & Research report \\
\hline Defining & $\begin{array}{l}\text { Data synthesis and artefact } \\
\text { creation }\end{array}$ & $\begin{array}{l}\text { Opportunity maps } \\
\text { Personas } \\
\text { Customer journey maps } \\
\text { Research videos } \\
\text { Infographic }\end{array}$ \\
\hline Designing & $\begin{array}{l}\text { Iterative sketching (wire } \\
\text { frames) } \\
\text { Co-design workshop }\end{array}$ & $\begin{array}{l}\text { Function overview } \\
\text { Wire frames } \\
\text { User stories } \\
\text { Video prototype } \\
\text { Future storyboard } \\
\text { Quick wins }\end{array}$ \\
\hline Delivery & $\begin{array}{l}\text { Communication of findings and } \\
\text { deliverables through email, and } \\
\text { a presentation }\end{array}$ & $\begin{array}{l}\text { PowerPoint presentation } \\
\text { HTML deliverables site }\end{array}$ \\
\hline
\end{tabular}


Table 2. Overview of project artefacts.

\begin{tabular}{|c|c|}
\hline Artefact & Description \\
\hline Research report & $\begin{array}{l}\text { The research report communicated the key insights about the user group } \\
\text { mapped to the associated findings and recommendations. Insights } \\
\text { comprised broad generalisations, and the findings provided evidence of the } \\
\text { insights. Additional information was provided and recommendations (e.g., } \\
\text { suggestions of factors to change or enact) were made to address both the } \\
\text { insights and findings. The artefacts functioned to document the findings } \\
\text { and substantiate the design recommendations, while the recommendations } \\
\text { were presented in a format common to the organisation. }\end{array}$ \\
\hline $\begin{array}{l}\text { Opportunity } \\
\text { map }\end{array}$ & $\begin{array}{l}\text { Visual maps were constructed to understand customer work activities, and } \\
\text { initial freehand sketches were later translated into designed artefacts. One } \\
\text { illustrates the customers' activities and the other identifies high-level } \\
\text { capabilities to support these activities, including a summary of the benefits } \\
\text { to the organisation. Initially created as conceptual tools to consider and } \\
\text { synthesise customer needs, these maps were used to document and } \\
\text { communicate the work activities of customers and to identify opportunities } \\
\text { for service improvement. }\end{array}$ \\
\hline
\end{tabular}

Persona Three personas were created to reflect three different customer types based on the type (and complexity) of the products sold. Data from customer interviews were used to guide recruitment for the co-design workshop, while personas were intended to inform future design work relating to both this initiative and these customers.

Customer Data from the internal workshop and qualitative interviews were translated journey maps into customer journey maps, including maps of the tasks, artefacts, systems and tools used. Customers' needs, pain points and opportunities were then mapped to the different stages of the customer journey. Three maps representing the ordering and activation processes for three distinct products communicated the complexity of the existing processes. These maps provided a framework for the organisation to reconsider associated processes and systems.

Infographic The infographic translated complex quantitative data to a broad audience group in an accessible way. This presented the number of support calls made to the customer call centre, information about the associated revenue derived by the organisation in relation to each product, and the number of customers by state. The infographic presented statistics by showing that i) the customer group contributed a significant amount of revenue to the organisation; and ii) if the organisation improved their ordering services, the call centres would become more efficient and the organisation's net revenue would consequently increase. This artefact was persuasive, as it illustrated the potential value of investing in a revised online ordering service.

Research videos

Two one and a half minute research videos were created on the qualitative research undertaken. Each video displayed 8-10 verbatim quotes from various staff and customer research participants. These videos sought to create empathy for customers and simply and persuasively communicate the issues consumers encountered when ordering products. The videos revealed issues with the current ordering processes and which tools were onerous. 


\begin{tabular}{|c|c|}
\hline Artefact & Description \\
\hline $\begin{array}{l}\text { Function } \\
\text { overview }\end{array}$ & $\begin{array}{l}\text { The function overview provided a brief summary of the functions for the } \\
\text { recommended portal. This mapped opportunities identified in the } \\
\text { opportunity maps and sought to provide an easily digestible overview of } \\
\text { the proposed organisation's service capabilities. }\end{array}$ \\
\hline Wire frames & $\begin{array}{l}\text { A series of annotated wire frames were delivered as a PDF file to visually } \\
\text { communicate the features of the portal rather than specific patterns and } \\
\text { interactions. }\end{array}$ \\
\hline $\begin{array}{l}\text { Video } \\
\text { prototype }\end{array}$ & $\begin{array}{l}\text { In the video prototype, a user called 'Janine' talked the audience through } \\
\text { an animation of wire frames, describing a proposed system in terms of its } \\
\text { benefits. These addressed many of the pain points expressed by other } \\
\text { artefacts (e.g., the journey maps and personas). The lead designer held that } \\
\text { wire frames were not easily accessible to non-technical audiences. Thus, } \\
\text { the video prototype was created to present the designs in an accessible way } \\
\text { that was appropriate to a broad range of stakeholders. }\end{array}$ \\
\hline User stories & $\begin{array}{l}\text { Agile user stories (e.g., 'As a customer I can check the status of an order so } \\
\text { that I can arrange access for technicians installing network infrastructure') } \\
\text { were set out in an Excel spreadsheet to correspond with the features in the } \\
\text { wire frames. The user stories sought to communicate the scope of the } \\
\text { design and required technical integration to enable the development of the } \\
\text { project management staff. }\end{array}$ \\
\hline Quick wins & $\begin{array}{l}\text { In an Excel spreadsheet, the quick wins (i.e., the actions that the } \\
\text { organisation could implement immediately to improve the existing service } \\
\text { for a group) were listed. Every quick win could be executed immediately } \\
\text { and without funding. }\end{array}$ \\
\hline $\begin{array}{l}\text { Future } \\
\text { storyboard }\end{array}$ & $\begin{array}{l}\text { Two future storyboards (depicting the scenarios in use) showed a tracking } \\
\text { feature and a mobile ordering process using a tablet. These artefacts } \\
\text { communicate service concepts in relation to their use context. }\end{array}$ \\
\hline
\end{tabular}

\section{Results}

The study found that the use of design artefacts in customer-centric innovation activities leads to organisational change. Our results show that design artefacts support social mediation and are critical in enabling and mediating change. In Sections 5.1 to 5.5, we explore five roles and propose their relationships with customer-centric innovation and organisational change in relation to the case study.

\subsection{Proposition 1: Design Artefacts Function as Customer Empathy Enablers}

Participants in the study agreed that adopting a customer-centric perspective was vital to company processes. However, like those in previous studies (e.g., Galbraith 2005; 
Meyer and Schwager 2007; Shah et al. 2006), the participants in the present study did perceive the shift towards customer-centricity as challenging. Participants also reported that creating project artefacts (e.g., personas), rather than writing bullet point lists for PowerPoint presentations, gave the customer research a human voice and face, and communicated customers' frustrations and needs in an accessible and engaging way. Personas were considered particularly instructive in communicating information about customers' behaviours as well as qualitative and behavioural information from their perspectives.

When reviewing the videos created from customer interviews (another key artefact in the study), participants noted that they felt more directly engaged with the artefacts and that unlike documents, which have to be read, it was impossible to scan videos. Videos evoked much more direct exposure to customer pain points. Notably, the use of first-person verbatim quotations facilitated customer empathy, while the visual artefacts motivated sharing between formal and informal social networks. Thus, evidence was found on the effectiveness of design artefacts and their value in understanding customers and creating empathy. Additionally, participants noted that such engaging visual formats would be useful in aiding cultural change within the organisation.

Other authors have considered how design artefacts can evoke feelings of empathy (e.g., Mattelmäki 2008; Van Rijn et al. 2011). However, in the case study it was discovered that organisational outcomes required the collective participation of many people and that empathy was not only valuable within the design team, but also affected people involved in other projects. Due to their aesthetic dimensions, design artefacts link with subjective emotions, empathy, intuition and judgement (Fulton Suri 2008; Rafaeli and Vilnai-Yavetz 2004a). Participants in the study noted how the novel 
visual formats of the artefacts motivated them to share information with their colleagues. Their rich visual design addressed a number of issues related to less engaging formats and encouraged feelings of customer empathy across broad organisational audiences.

\subsection{Proposition 2: Design Artefacts Facilitate and Activate Collaboration}

Participants reported that collaborations among cross-functional business groups were critical to innovation processes. Indeed, participation in the project activities was mostly voluntary; however, the design artefacts further activated the involvement of nondesigners in the company. Many participants noted that encouraging other colleagues to contribute and their overall engagement with and advocacy for the innovation initiatives were both critical and challenging.

Artefacts, such as videos and presentations, were shared with managers from other areas to communicate issues related to poor customer experiences and to gain their support. Once completed, some artefacts stimulated the interest of several other stakeholders in the project and its outcomes, and this ultimately led to the development of more ideas and associated change processes.

Using the artefacts to activate collaboration and participation in the innovation context of the project was critical. Motivated by human agency (Maidique 1980; Rogers 1995), team members became agents who enacted change by interacting and networking within and across the organisation. Thus, it appears that by creating empathy, artefacts encourage and activate collaboration.

Evidently, the artefacts mediated the dialogue between designers and other members of the organisation by codifying and communicating knowledge. Visual artefacts (e.g., customer journey maps) provided the bases for discussions about customer-centric changes beyond the project context. For example, one process 
improvement specialist stated that she would use artefacts within workshops as a 'springboard' for conversations about improvements related to other associated processes.

\subsection{Proposition 3: Design Artefacts Provide Reflective Sense-making}

\section{Frameworks}

We observed that members of the project team used artefacts as reflective sense-making tools to understand, frame problems and communicate. Sense-making refers to the process by which individuals or groups make sense of information. The artefacts (e.g., the opportunity maps or journey maps) created for this project assisted non-design staff members to understand and appreciate new models of thinking about customers and the difficulties that customers face using the current products and services.

For example, the lead designer created opportunity maps and personas to help demonstrate customers' work practices and to conceptualize how the organisation could add value to these practices for them, in turn. These artefacts were initially used to understand the context and needs of customers; however, they evolved throughout various consultations until they ultimately served as a framework for reflection and a synthesis of key customer tasks, needs and improvement opportunities. Thus, the artefacts became structures through which the design team could reflect and refine their understandings of the project. Similarly, the journey maps were used to combine different data into one visual artefact over time. This enabled the team to synthesize, consider, talk about and gain insights into the data, while the non-design staff members could better understand current user experiences and related systems.

\subsection{Proposition 4: Design Artefacts Play Persuasive Roles}

In the present case study, artefacts assumed an implicit persuasive role. From executives 
to the frontline staff delivering the products or services, and those involved with implementation to customers, every stakeholder needs to be engaged, informed or convinced in some way at some point. Herein, team members employed artefacts as persuasive tools. For example, some did so to encourage senior executives to fund the project, while others used artefacts to support their recommendations.

Additionally, team members found that the artefacts were very effective in communicating key issues and complex financial information. For example, the infographic clearly showed the financial benefits related to funding the proposed platform, while the videos provided evidence as to why the ordering service needed to be improved. Wagner (2000) suggests use of a 'persuasive artefact'; however, her observation is based on collaborative architectural work within a single community of practice. Conversely, in this study it was observed that artefacts enable social mediations between communities of practice across long-term innovation initiatives.

This study also revealed how artefacts play political roles. One participant emphasized the importance of gaining support from the 'right' stakeholders to progress a project and noted that the videos had been very helpful in increasing the interests of stakeholders.

\subsection{Proposition 5: Design Artefacts Effectively Communicate Customer-centric and Design Knowledge}

The project participants used artefacts to effectively communicate a customer-centric perspective. For example, individuals showed videos of customer interviews to executives, national sales staff and call centre representatives to demonstrate customers' perspectives in the design phase. Both videos and personas were used to educate new staff about central customer characteristics and needs. Further, even after the project had finished, members of the organisation continued to use the same artefacts to 
describe key customer attributes. Indeed, management theory supports the role of artefacts in organisational learning, which often rests upon social processes that are mediated by artefacts (Boreham and Morgan 2004; Weick and Roberts 1993).

The artefacts were also used tactically (to explain the 'how') and strategically (to help individuals envision 'what could be'). For example, a conceptual video prototype, which had been created to explain the design concept to staff members with no or limited technical knowledge, was later used to share a customer-centric vision to the organisation. Thus, artefacts can function to motivate action, enable strategy (Eppler and Platts 2009; Spee and Jarzabkowski 2009) and to bridge current and future states. Artefacts are also often used to share a future vision and to activate participation, collaboration, advocacy and internal alignment because of their engaging visual forms. In the case study, the artefacts linked specific actions or outcomes to a broader strategic narrative.

When artefacts are shared voluntarily and discussed widely, they can become mechanisms to express culture and enact change (Carlile 2006; Fiol and O’Conner 2006). For example, in this study participants recalled how they learned about the project 'road show' through formal and informal networks. This illustrates the social character of knowledge sharing and the value of social networks in distributing knowledge within organisations (Dasgupta and Gupta 2009; Hutchins 1995; Lave and Wenger 1991; Tsoukas 1996). Artefacts can become symbols of a new customer-centric culture (Boreham and Morgan 2004) merely by being discussed. Thus, design artefacts appear to strengthen informal work relationships, organisational learning and cultural transformations towards customer-centricity.

\section{Discussion and Conclusion}

We argue that design artefacts have five significant and distinct sociopolitical and 
sociocultural roles. Specifically, it is contented that design artefacts i) act as customer empathy enablers; ii) function as collaboration facilitators and activators; iii) provide reflective sense-making frameworks; iv) are persuasive tools; and v) are design- and customer-centric knowledge communicators.

Customer empathy encourages (i) customer-centric judgements, behaviours and the advocacy required to implement innovative changes, such as changes to processes and organisational structures (Manning, Bodine and Bernoff 2012). Empathy enables people to suspend judgement and comprehend paradigmatic differences, and further fosters more enlightened relationships and goodwill within organisations (Natale and Sora 2010). As a connectedness-organising mechanism, empathy can assist staff members to recognize the interconnectedness and interrelationships between collective actions (Pavlovich and Krahnke 2012). Empathy also facilitates shared meanings that can create, sustain or change organisational cultures (Cook and Yanow 1993).

We also found that design artefacts can motivate customer-centric collective actions by facilitating far-reaching empathy for customers and enabling customercentric judgements and behaviours. Design artefacts can shift thinking from matters of sheer usability towards a deeper understanding of human dignity, thus, positively affecting the thoughts and actions of individuals (Buchanan 2015) in support of customer-centric collective outcomes.

As collaboration facilitators and activators (ii), design artefacts also transform understandings and actions by enabling people to identify contradictions and uncertainties related to organisational processes (Engeström 2001). Artefacts are not merely static knowledge repositories (Carlile 2002); rather, they are dynamic and active tools. Individuals use artefacts of knowing (Ewenstein and Whyte 2007) to exemplify, translate and contribute to their understandings. When mediated by artefacts, knowledge 
and activity as well as communicative actions (Orlikowski 2002) transform and facilitate innovation (Dasgupta and Gupta 2009; du Plessis 2007; MacPherson, Jones and Oakes 2006; Miettinen and Virkkunen 2005). Proposition 2 describes the mediatory and enabling role of artefacts.

The value of visual practices in sense-making and synthesis (iii) is well established (Kolko 2010; Krippendorff 1989). Our results confirm previous findings and that such practices enhance sense-making processes by making the abstract more concrete, improving communication and building knowledge, and enabling complex and non-tangible concepts to be understood (Michela and Floricel 2012; Oster 2009). The visual artefacts in this study aided sense-making, shifted mental models and supported organisational change processes (Senge et al. 2005). Further, sharing within and between organisational networks led to collective sense-making (Orlikowski 2002). The design artefacts provided cognitive frameworks to various actors, supported problem-framing processes (Beckman and Barry 2007; Dorst 2011) and enabled the organisation to both identify and solve customer problems, and to innovate. Thus, as suggested by Proposition 3, artefacts are valuable 'things-to-think-with' (Brandt 2007). As persuasive tools (iv), brokering artefacts to stakeholders at different times represents a political activity (Carlile 2002; Kimble, Grenier and Goglio-Primard 2010). It has been suggested that politics only play out during the final phases of a project (Carlile 2004); however, we found that politics and the management of social relations were significant throughout the process. Thus, artefacts play important, persuasive and additional roles in the innovation, design and implementation phases of projects. Artefacts also affect project advocacy, project continuation, consensus building, knowledge sharing and organisational change processes. Evidently, persuasive artefacts 
improve both product and service provision, supporting managerial processes, creating efficiency and facilitating financial effects, in turn.

Finally, customer-centric knowledge, expressed through engaging and accessible design artefacts, provided the organisation in this paper with new and effective boundary objects, which allowed people to engage with, talk through and discuss customer-centricity. Thus, artefacts play enabling roles, act as change agents and support innovation and transformation (v).

Overall, this study sought to explore the value of design artefacts in creating customer-centric organisations. It contributes to design education literature, discourse about innovation management, customer-centric organisational change, design practice and design economics. In turn, the potential value and roles of design artefacts outside the bounds of singular design projects or isolated design processes have been demonstrated.

\section{Limitations and Future Research}

In this paper, the five distinct roles of artefacts were considered. By virtue of their rich, visual, novel and engaging formats, artefacts are likely to be shared more easily in informal organisational arrangements (e.g., among cross-functional teams). Artefacts provide an accessible and applicable way to communicate tacit needs and other customer-centric insights, and further inspire customer-centric behaviours and stimulate cultural shifts in organisations. Thus, our findings generally showed the value of design artefacts in customer-centric organisational change. We also demonstrate how some specific design artefacts supported the organisation to deliver a more marketoriented offering, and enabled customer-centric awareness among diverse stakeholders, thus, facilitating efficiency and profitability. However, further empirical research is 
required to validate the propositions developed in this paper and to determine the conditions under which design artefacts spur customer-centric organisational change.

A limitation for this study was that the case organisation had an established design practice and executive support for both customer-centric organisational change and design-driven innovation. It was only feasible to perform a single case study, preventing cross-comparison between cases. It would be instructive to undertake associated studies in other organisations to find more generalisable insights about the role of artefacts in relation to customer-centric organisational change within similar projects and contexts.

Our research raises a number of questions about the factors and capabilities needed to transition to customer-centricity using design artefacts. Factors such as knowledge management capabilities, organisational culture and absorptive capacity (Cohen and Levinthal 1990) could affect the ability of design artefacts to affect organisational transformations. Additionally, artefacts need to be recognized and promoted by leadership (Aftab 2013; Aftab, Young and MacLarty 2013). Hence, executive support for the use of design artefacts shows their widespread application and effects (Bailey 2012).

Organisations also need to develop the necessary capabilities to use design artefacts as mediatory and enabling tools. Notably, training and participation in design processes can facilitate familiarity with customer-centric design artefacts (Junginger 2005). For example, this case study informed the creation of a pedagogical framework that was designed to support the development of design artefacts (Wechsler 2017). It too revealed how the development of well-considered design artefacts can provide professionals with an opportunity to adopt more strategic roles (Kimbell 2010). 


\section{References}

Aftab, Mersha. 2013. "Design as a Functional Leader: A Case Study to Investigate the Role of Design as a Potential Leading Discipline in Multinational Organisations." PhD diss., University of Northumbria.

Aftab, Mersha, Robert Young, and Elizabeth MacLarty. 2013. "Design as a Functional Leader: A Case Study of Philips to Investigate the Potential of Design as a Leading Functional Discipline.” Paper presented at the Crafting the Future: 10th European Academy of Design Conference, Gothenburg, April 17-19.

Bailey, Stuart G. 2012. "Embedding Service Design: The Long and the Short of It." In Proceedings of the 3rd Service Design and Service Innovation Conference, ServDes.2012, edited by Päivi J. Tossavainen, Milla Harjula and Stefan Holmlid, 31-42. Linköping: Linköping University Electronic Press

Beckman, Sara, and Michael Barry. 2007. "Innovation as a Learning Process:

Embedding Design Thinking." California Management Review 50 (1): 25-56. doi:10.2307/41166415.

Boreham, Nick, and Colin Morgan. 2004. "A Sociocultural Analysis of Organisational Learning." Oxford Review of Education 30 (3): 307-325. doi:10.1080/0305498042000260467.

Brandt, Eva. 2007. "How Tangible Mock-ups Support Design Collaboration." Knowledge, Technology and Policy 20 (3): 179-192. doi:10.1007/s12130-0079021-9.

Buchanan, Richard. 2015. "Worlds in the Making: Design, Management, and the Reform of Organizational Culture.” She Ji: Journal of Design, Economics, and Innovation 1 (1): 5-21. doi:10.1016/j.sheji.2015.09.003.

Bucolo, Sam, Cara Wrigley, and Judy Matthews. 2012. “Gaps in Organizational Leadership: Linking Strategic and Operational Activities Through Design-led Propositions.” Design Management Journal 7 (1): 18-28. doi:10.1111/j.19487177.2012.00030.x.

Carlile, Paulie R. 2002. “A Pragmatic View of Knowledge and Boundaries: Boundary Objects in New Product Development." Organization Science 13 (4): 442-455. https://www.jstor.org/stable/3085976. 
Carlile, Paulie R. 2004. “Transferring, Translating, and Transforming: An Integrative Framework for Managing Knowledge Across Boundaries." Organization Science 15 (5): 499-616. doi:10.1287/orsc.1040.0094.

Carlile, Paulie R. 2006. “Artifacts and Knowledge Negotiation Across Domains.” In Artifacts and Organizations: Beyond Mere Symbolism, edited by Anat Rafaeli and Michael G. Pratt, 101-117. Mahwah: Lawrence Erlbaum.

Clegg, Stewart R., Jochen Schweitzer, Andrea Whittle, and Christos Pitelis. 2017. Strategy: Theory and Practice. 2nd ed. London: Sage.

Cohen, Wesley M., and Daniel A. Levinthal. 1990. “Absorptive Capacity: A New Perspective on Learning and Innovation." Administrative Science Quarterly 35 (1): 128-152. doi:10.2307/2393553.

Cook, Scott D. N., and Dvora Yanow. 1993. "Culture and Organizational Learning." Journal of Management Inquiry 2 (4): 373-390. doi:10.1177/105649269324010.

Cooper, Rachel, Sabine Junginger, and Thomas Lockwood. 2011. The Handbook of Design Management. Oxford: Berg.

Dasgupta, Meeta, and Rajen K. Gupta. 2009. "Innovation in Organizations: A Review of the Role of Organizational Learning and Knowledge Management." Global Business Review 10 (2): 203-224. doi:10.1177/097215090901000205.

Dorst, Kees. 2011. “The Core of 'Design Thinking' and its Application.” Design Studies 32 (6): 521-532. doi:j.destud.2011.07.006.

du Plessis, Marina. 2007. "The Role of Knowledge Management in Innovation." Journal of Knowledge Management 11 (4): 20-29. doi:10.1108/13673270710762684.

Dunne, Keiran J. 2011. "From Vicious to Virtuous Cycle: Customer-focused Translation Quality Management Using ISO 9001 Principles and Agile Methodologies." In Translation and Localization Project Management: The Art of the Possible, edited by Keiran J. Dunne and Elena S. Dunne, 153-188. Amsterdam: John Benjamins.

Elsbach, Kimberly D., and Ileana Stigliani. 2018. "Design Thinking and Organizational Culture: A Review and Framework for Future Research." Journal of Management 44 (6): 2274-2306. doi:10.1177/0149206317744252.

Engeström, Yjrö. 1999. “Activity Theory and Individual and Social Transformation.” In Perspectives on Activity Theory, edited by Yrjö Engeström, Reijo Miettinen and Raija-Leena Punamäki, 19-38. Cambridge: Cambridge University Press. 
Engeström, Yjrö. 2001. "Expansive Learning at Work: Toward an Activity Theoretical Reconceptualization.” Journal of Education and Work 14 (1): 133-156. doi:10.1080/13639080020028747.

Eppler, Martin J., and Ken W. Platts. 2009. "Visual Strategizing: The Systematic Use of Visualization in the Strategic-planning Process.” Long Range Planning 42 (1): 42-74. doi:10.1016/j.lrp.2008.11.005.

Ewenstein, Boris, and Jennifer K. Whyte. 2007. "Visual Representations as 'Artefacts of Knowing'." Building Research and Information 35 (1): 81-89. doi:10.1080/09613210600950377.

Fiol, Marlene, and Ed J. O’Connor. 2006. “Stuff Matters: Artifacts, Social Identity, and Legitimacy in the US Medical Profession.” In Artifacts and Organizations: Beyond Mere Symbolism, edited by Anat Rafaeli and Michael G. Pratt, 241-257. Mahwah: Erlbaum.

Fulton Suri, J. 2008. "Informing Our Intuition: Design Research for Radical Innovation." Rotman Magazine, Winter: 52-57.

Galbraith, Jay R. 2005. Designing the Customer-centric Organization: A Guide to Strategy, Structure and Process. San Francisco: Jossey-Bass.

Geertz, Clifford. 1973. The Interpretation of Cultures. New York: Basic Books. Hanington, Bruce, and Bella Martin. 2012. Universal Methods of Design: 100 Ways to Research Complex Problems, Develop Innovative Ideas, and Design Effective Solutions. Beverly: Rockport Publishers.

Hargadon, Andrew, and Robert I. Sutton. 2000. "Building An Innovation Factory." Harvard Business Review 78 (3): 157-166. https://hbr.org/2000/05/building-aninnovation-factory-2.

Henderson, Kathryn. 1991. "Flexible Sketches and Inflexible Data Bases: Visual Communication, Conscription Devices, and Boundary Objects in Design Engineering." Science, Technology, \& Human Values 16 (4): 448-473. doi:10.1177/016224399101600402.

Henderson, Kathryn. 1999. On Line and On Paper: Visual Representations, Visual Culture and Computer Graphics in Design Engineering. Cambridge: MIT Press. Hutchins, Edwin. 1995. Cognition in the Wild. Cambridge: MIT Press.

Johnston, Robert, and Xiangyu Kong. 2011. "The Customer Experience: A Road-map for Improvement.” Managing Service Quality: An International Journal 21 (1): 5-24. doi:10.1108/09604521111100225. 
Junginger, Sabine. 2005. "A Different Role for Human-centered Design Within the Organization." Paper presented at the Proceedings of the 6th Annual Conference of the European Academy of Design, Bremen, March.

Kimbell, Lucy. 2010. "From User-centred Design to Designing for Service." Paper presented at Design Management Conference, London, September 8.

Kimble, Chris, Corinne Grenier, and Karine Goglio-Primard. 2010. "Innovation and Knowledge Sharing Across Professional Boundaries: Political Interplay Between Boundary Objects and Brokers." International Journal of Information Management 30 (5): 437-444. doi:10.1016/j.ijinfomgt.2010.02.002.

Knorr Cetina, Karin. 1997. "Sociality with Objects: Social Relations in Postsocial Knowledge Societies." Theory, Culture and Society 14 (4): 1-30. doi:10.1177/026327697014004001.

Kolko, Jon. 2010. “Abductive Thinking and Sensemaking: The Drivers of Design Synthesis.” Design Issues 26 (1): 15-28. doi:10.1162/desi.2010.26.1.15.

Krefting, Laura. 1991. "Rigor in Qualitative Research: The Assessment of Trustworthiness." American Journal of Occupational Therapy 45 (3): 214-222. doi:10.5014/ajot.45.3.214.

Krippendorff, Klaus. 1989. "On the Essential Contexts of Artifacts or on the Proposition that 'Design is Making Sense (of Things)'.” Design Issues 5 (2): 9-39. doi: $10.2307 / 1511512$.

Lave, Jean, and Etienne Wenger. 1991. Situated Learning: Legitimate Peripheral Participation. Cambridge: Cambridge University Press.

Leung, Linda, Natalia Nikolova, Jochen Schweitzer, Tony Golsby-Smith, Tracy Whybrow, and Kevin Jurd. 2016. The View from the Top-2016 Innovation Report: A Conversation with Chairs and CEOs of 20+ Major Corporations on the State of Innovation in Australia. Sydney: University of Technology Sydney. Liedtka, Jeanne, and Tom Ogilvie. 2011. Designing for Growth: A Design Thinking Tool Kit for Managers. New York: Columbia University Press.

MacDonald, Susan. 1994. Professional Academic Writing in the Humanities and Social Sciences. Illinois: Southern Illinois University Press.

Macpherson, Allan, Oswald Jones, and Helen Oakes. 2006. "Mediating Artefacts, Boundary Objects and the Social Construction of Knowledge.” Paper presented at the First International Conference on Organizational Learning, Knowledge and Capabilities, OLKC 1, University of Warwick, March 20-22. 
Mafe, Daniel J, and Andrew R. Brown. 2006. "Emergent Matters: Reflections on Collaborative Practice-led Research." Paper presented at the Speculation and Innovation Conference, Brisbane, Queensland University of Technology, April. Maidique, Modesto. 1980. "Entrepreneurs, Champions and Technological Innovation." Sloan Management Review 21 (2): 59-76. http://ezproxy.lib.uts.edu.au/login?url=https://search-proquestcom.ezproxy.lib.uts.edu.au/docview/206796839?accountid=17095

Manning, Harley, Kerry Bodine, and Josh Bernoff. 2012. Outside in: The Power of Putting Customers at the Center of Your Business. New York: Houghton Mifflin Harcourt.

Mattelmäki, Tuuli. 2008. "Probing for Co-exploring.” CoDesign 4 (1): 65-78. doi:10.1080/15710880701875027.

Meyer, Chris, and Andre Schwager. 2007. "Understanding Customer Experience." Harvard Business Review 85 (2): 116-126. https://hbr.org/2007/02/understanding-customer-experience.

Michela, John, and Serghei Floricel. 2012. "Collaboration for Innovation through Knowledge Representation.” Paper presented at the XXIII ISPIM ConferenceAction for Innovation: Innovating from Experience, Barcelona, June 17-20. Miettinen, Reijo, and Jaakko Virkkunen. 2005. "Epistemic Objects, Artefacts and Organizational Change.” Organization 12 (3): 437-456. doi:10.1177/1350508405051279.

Miles, Matthew B., and A. Michael Huberman. 1994. Qualitative Data Analysis. 2nd ed. Thousand Oaks: Sage.

Mills, Jane, Ann Bonner, and Karen Francis. 2006. “The Development of Constructivist Grounded Theory.” International Journal of Qualitative Methods 5 (1): 25-35. doi:10.1177/160940690600500103.

Natale, Samuel, and Sebastian Sora. 2010. "Ethics in Strategic Thinking: Business Processes and the Global Market Collapse.” Journal of Business Ethics 94 (3): 309-316. doi:10.1007/s10551-009-0270-2.

Orlikowski, Wanda J. 2002. "Knowing in Practice: Enacting a Collective Capability in Distributed Organizing." Organization Science 13 (3): 249-273. doi:10.1287/orsc.13.3.249.2776. 
Orlikowski, Wanda J. 2006. "Material Knowing: The Scaffolding of Human Knowledgeability.” European Journal of Information Systems 15 (5): 460-466. doi:10.1057/palgrave.ejis.3000639.

Orlikowski, Wanda J. 2007. "Sociomaterial Practices: Exploring Technology at Work." Organization Studies 28 (9): 1435-1448. doi:10.1177/0170840607081138.

Oster, Gary. 2009. "Recasting Corporate Use of Prototypes.” Review of International Comparative Management 10 (2): 218-228. http://www.rmci.ase.ro/no10vol2/Vol10_No2_Article2.pdf.

Pavlovich, Kathryn, and Keiko Krahnke. 2012. "Empathy, Connectedness and Organisation." Journal of Business Ethics 105 (1): 131-137. doi:10.1007/s10551-011-0961-3.

Perry, Mark, and Duncan Sanderson. 1998. "Coordinating Joint Design Work: The Role of Communication and Artefacts." Design Studies 19 (3): 273-288. doi:10.1016/S0142-694X(98)00008-8.

Rafaeli, Anat, and Iris Vilnai-Yavetz. 2004a. "Emotion as a Connection of Physical Artifacts and Organizations." Organization Science 15 (6): 671-686. https://www.jstor.org/stable/30034769.

Rafaeli, Anat, and Iris Vilnai-Yavetz. 2004b. "Instrumentality, Aesthetics and Symbolism of Physical Artifacts as Triggers of Emotions." Theoretical Issues in Ergonomics Science 5 (1): 91-112. doi:10.1080/1463922031000086735.

Rafaeli, Anat, and Iris Vilnai-Yavetz. 2006. "Managing Artifacts to Avoid Artifact Myopia." In Artifacts and Organizations: Beyond Mere Symbolism, edited by Anat Rafaeli and Michael G. Pratt, 9-22. Mahwah: Erlbaum.

Robson, Colin. 1995. Real World Research: A Resource for Social Scientists and Practitioner-Researchers. Oxford: Blackwell.

Rogers, Everett M. 1995. Diffusion of Innovations. 4th ed. New York: The Free Press. Roth, Wolf-Michael, and Michelle K. McGinn. 1998. "Inscriptions: Toward a Theory of Representing as Social Practice." Review of Educational Research 68 (1): 3559. doi:10.3102/00346543068001035.

Schrage, Michael. 1993. "The Culture(s) of Prototyping.” Design Management Institute 4 (1): 55-65. doi:10.1111/j.1948-7169.1993.tb00128.x.

Schweitzer, Jochen. 2014. "Leadership and Innovation Capability Development in Strategic Alliances.” Leadership and Organization Development Journal 35 (5): 442-469. doi:10.1108/LODJ-01-12-0001. 
Schweitzer, Jochen, Lars Groeger, and Leanne Sobel. 2016. "The Design Thinking Mindset: An Assessment of What We Know and What We See in Practice." Journal of Design, Business and Society 2 (1): 71-94. doi:10.1386/dbs.2.1.71_1. Seaman, Jayson. 2008. "Adopting a Grounded Theory Approach to Cultural-historical Research: Conflicting Methodologies or Complementary Methods?" International Journal of Qualitative Methods 7 (1): 1-17. doi:10.1177/160940690800700101.

Senge, Peter, C. Otto Scharmer, Joseph Jaworski, and Betty S. Flowers. 2005. Presence: Exploring Profound Change in People, Organizations and Society. London: Nicholas Brealey.

Shah, Denish, Roland T. Rust, Ananthanarayanan Parasuraman, Richard Staelin, and George S. Day. 2006. "The Path to Customer Centricity.” Journal of Service Research 9 (2): 113-124. doi:10.1177/1094670506294666.

Spee, Andreas P., and Paula Jarzabkowski. 2009. "Strategy Tools As Boundary Objects." Strategic Organization 7 (2): 223-232. doi:10.1177/1476127009102674.

Stake, Robert E. 1995. The Art of Case Study Research. Thousand Oaks: Sage. Star, Susan L., and James R. Griesemer. 1989. “Institutional Ecology, 'Translations' and Boundary Objects: Amateurs and Professionals in Berkeley's Museum of Vertebrate Zoology, 1907-39." Social Studies of Science 19 (3): 387-420. doi:10.1177/030631289019003001.

Tsoukas, Haridimos. 1996. "The Firm as a Distributed Knowledge System: A Constructionist Approach.” Strategic Management Journal 17 (Suppl. 2): 1125. doi:10.1002/smj.4250171104.

Van Rijn, Helma, Froujke S. Visser, Pieter J. Stappers, and Asli D. Özakar. 2011. "Achieving Empathy with Users: The Effects of Different Sources of Information." CoDesign 7 (2): 65-77. doi:10.1080/15710882.2011.609889.

Veyzer, Robert, and Brigitte Borja De Mozata. 2005. “The Impact of User-orientated Design on New Product Development: An Examination of Fundamental Relationship.” Journal of Product Innovation Management 22 (2): 128-143. doi:10.1111/j.0737-6782.2005.00110.x.

Wagner, Ina. 2000. "Persuasive Artefacts in Architectural Design and Planning.” In Collaborative Design, edited by Stephen A. R. Scrivener, Linden J. Ball and Andree Woodcock, 379-389. London: Springer. 
Wechsler, Jacqueline. 2017. "Scaffolding Innovation with Design Artefacts that Enable Others to Do their Work." In Visual Tools for Developing Cross-disciplinary Collaboration, Innovation and Entrepreneurship Capacity, edited by Selena Griffith, Kate Carruthers and Martin Bliemel, 197-222. Champaign: Common Ground.

Weick, Karl E., and Karlene H. Roberts. 1993. "Collective Mind in Organizations: Heedful Interrelating on Flight Decks.” Administrative Science Quarterly 38 (3): 357-381. doi:10.2307/2393372.

Wenger, Etienne. 1998. Communities of Practice: Learning, Meaning, and Identity. Cambridge: Cambridge University Press.

Wenger, Etienne. 2000. "Communities of Practice and Social Learning Systems." Organization 7 (2): 225-246. doi:10.1177/135050840072002.

Yin, Robert. 2003. Case Study Research: Design and Methods. 3rd ed. Thousand Oaks: Sage. 